\title{
Penanggulangan Kesehatan Dalam Kondisi Pasca Bencana Dusun Ujung Indah, Desa Cilellang, Kecamatan Mallusettasi, Kabupaten
} Barru

\author{
Amran Nur ${ }^{*}$, Veronica Margareth Dampung ${ }^{2}$ \\ ${ }^{1}$ Biomedik Farmakologi, Fakultas Kedokteran, Universitas Khairun, Kota Ternate, Indonesia. \\ ${ }^{2}$ Farmasi, DIII Farmasi, STIKES Pelamonia Kesdam VII Wirabuana, Makassar, Indonesia.
}

\section{Article Info}

Received : 04-03-2020

Revised : 15-04-2020

Accepted: 18-04-2020

\begin{abstract}
Indonesia has been declared as one of the most disaster-prone countries according to the United Nations International Strategy for Disaster Reduction. Indonesia ranks $6^{\text {th }}$ among countries prone to disasters. Indonesia is prone to natural disasters such as earthquakes, tsunamis, volcanic eruptions, and others as well as non-natural disasters such as floods, infectious diseases, forest fires, and others, as well as social disasters in the form of social conflicts in various regions. One of the concepts of disaster management is disaster risk management, At this stage, efforts should be made if a catastrophic event occurs, damage and losses with a large enough scale of impact can be avoided and minimized by mitigating education to the community. Because the location of this village is on the seashore and has a watershed that could threaten the safety of the population, therefore a health prevention socialization will be carried out if at any time an unwanted natural disaster occurs.
\end{abstract}

Keywords: natural disasters, Barru Districts, disaster risk, countermeasures.

Citation: Nur, A., \& Dampung, V. M. (2020). Penanggulangan kesehatan dalam kondisi pasca bencana Dusun Ujung Indah, Desa Cilellang, Kecamatan Mallusettasi, Kabupaten Barru. INDRA Jurnal Pengabdian kepada Masyarakat, 1(1), 11-14.

\section{Pendahuluan}

Bencana merupakan peristiwa yang mengancam kelangsungan hidup manusia dan memiliki dampak yang buruk bagi manusia. Dampak bencana alam antara lain: menimbulkan tekanan batin, kegelisahan (ketegangan), serta dapat menyebabkan seseorang mengalami berbagai gangguan kepribadian (Faradilla, 2018; Ningrum, 2015).

Undang-Undang No. 24 Tahun 2007 mendefinisikan bencana sebagai peristiwa atau rangkaian peristiwa yang mengancam dan mengganggu kehidupan dan penghidupan masyarakat yang disebabkan baik oleh faktor alam dan/atau faktor nonalam maupun faktor manusia sehingga mengakibatkan timbulnya korban jiwa manusia, kerusakan lingkungan, kerugian harta benda, dan dampak psikologis. Bencana dapat dibagi menjadi tiga kategori yaitu: Bencana alam adalah bencana yang diakibatkan oleh peristiwa atau serangkaian peristiwa yang disebabkan oleh alam antara lain berupa gempa bumi, tsunami, gunung meletus, banjir, kekeringan, angin topan, dan tanah longsor. Bencana nonalam adalah bencana yang diakibatkan oleh peristiwa atau rangkaian peristiwa nonalam yang antara lain berupa gagal teknologi, gagal modernisasi, epidemi, dan wabah penyakit. Bencana sosial adalah bencana yang diakibatkan oleh peristiwa atau serangkaian peristiwa yang diakibatkan oleh manusia yang meliputi konflik sosial antarkelompok atau antarkomunitas masyarakat, dan teror (Indonesia, 2007).

Indonesia telah dinyatakan sebagai salah satu negara paling rawan bencana menurut United Nations International Strategy for Disaster Reduction (UNISDR) dan menduduki urutan ke-6 di antara negara-negara 
yang rawan bencana (BAPPENAS, 2006; UNISDR, 2009). Kenyataan menunjukkan Indonesia tetap rentan terhadap bencana baik yang disebabkan oleh alam maupun nonalam, serta bencana sosial berupa konflik sosial di berbagai daerah (Putra \& Faisal, 2018).

Bencana merupakan fakta yang tidak dapat dihindari akan tetapi dapat diantisipasi atau diminimalkan dampaknya, pembagian peran yang jelas antara berbagai pihak yang terlibat dan pemanfaatan media komunikasi dapat mempercepat penyebaran informasi. Proses komunikasi secara terencana dan strategis yang dapat dilakukan seperti pemanfaatan media untuk mendukung pembuatan kebijakan yang efektif, partisipasi masyarakat, dan pelaksanaan proyek yang diarahkan pada kelestarian lingkungan. Hal ini menjelaskan bahwa sebuah komunikasi lingkungan sebagai interaksi dua arah dari proses sosial yang memungkinkan orang yang bersangkutan untuk memahami faktor-faktor lingkungan tertentu dan saling ketergantungan (Lestari, Kusumayudha, Paripurno, \& Ramadhaniyanto, 2016).

Dusun Ujung Indah merupakan dusun yang terletak di Desa Cilellang, Kecamatan Mallusettasi, Kabupaten Barru, Sulawesi Selatan. Dusun ini merupakan salah satu dusun yang rawan akan bencana alam, terutama banjir, tanah longsor dan tsunami. Hal ini disebabkan oleh letak geografis dusun ini berada di pinggir pantai dan dilalui oleh aliran sungai serta berhadapan langsung dengan laut lepas. Desa ini juga dikelilingi oleh bukit yang sebagian tanahnya sudah dikeruk untuk kepentingan pembangunan sehingga meninggalkan tebing tanah yang sangat mudah longsor bila terjadi hujan deras. Oleh sebab itu perlu dilakukan sosialisasi mengenai mitigasi bencana serta penanggulangan kesehatan pasca bencana di daerah tersebut.

\section{Metode}

Pengabdian menggunakan metode sosialisasi kepada masyarakat di Dusun Ujung Indah, Desa Cilellang, Kecamatan Mallusettasi, Kabupaten Barru. Adapun yang menjadi subjek utama sosialisasi adalah masyarakat di Dusun Ujung Indah. Alat yang digunakan dalam pengabdian ini meliputi alat presentasi, pengeras suara, serta alat dokumentasi untuk mendokumentasikan proses kegiatan sosialisasi.

Target luaran kegiatan pengabdian ini adalah meningkatnya pemahaman masyarakat tentang mitigasi bencana, pengetahuan tentang pemanfaatan bahan alam yang ada di sekitar lingkungan sebagai obat tradisional, khususnya jika terjadi peristiwa darurat (bencana alam). Selain itu, target lain adalah terciptanya kesadaran masyarakat tentang pentingnya memanfaatkan lahan untuk ditanami tumbuhan obat.

\section{Hasil dan Pembahasan}

Pada kegiatan pengabdian dilakukan penyuluhan mengenai Penanggulangan Masalah Kesehatan dalam Kondisi Pasca Bencana di Dusun Ujung Indah, Desa Cilellang, Kecamatan Mallusettasi, Kabupaten Barru. Kegiatan pengabdian ini bertujuan untuk menambah pengetahuan masyarakat tentang penanganan pertama yang dilakukan masyarakat jika sewaktu-waktu terjadi bencana alam, terutama dalam penanggulangan masalah kesehatan dan cara pengobatan daruratnya. Proses sosialisasi dapat dilihat pada gambar 1.

Dalam sosialisasi tersebut juga dijelaskan cara memanfaatkan bahan alam yang terdapat di sekitar lokasi desa tersebut agar masyarakat dapat melakukan pengobatan darurat bila terjadi bencana. Apabila kemudian desa tersebut terisolasi akibat bencana, warga desa mampu melakukan pertolongan pertama, misalnya memanfaatkan obat tradisional dalam menghilangkan nyeri (obat analgetik dari bahan alam), obat menurunkan gula darah dan yang lainnya (Nur, Fajar, \& Musdalifah, 2018).
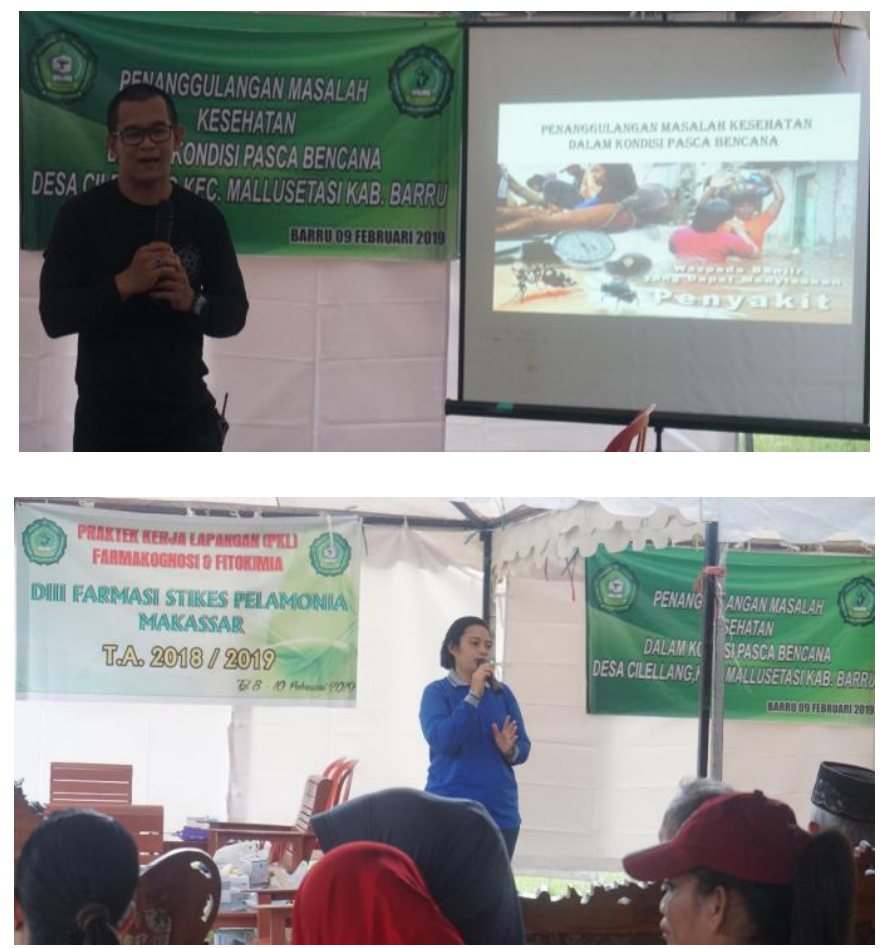

Gambar 1. Sosialisasi Penanganan Pasca Bencana oleh Pemateri.

Proses sosialisasi tentang Penanggulangan Masalah Kesehatan dalam Kondisi Pasca Bencana berjalan dengan lancar. Hal ini terlihat dari antusiasme masyarakat mengikuti sosialisasi tersebut, serta adanya beberapa pertanyaan yang disampaikan oleh masyarakat mengenai proses pengobatan ataupun pengobatan darurat apabila terjadi bencana yang tak diinginkan. Pada sosialisasi tersebut masyarakat juga 
diberikan pemahaman mengenai pentingnya mengetahui manfaat tumbuhan yang ada di sekitar mereka yang bermanfaat sebagai tumbuhan obat. Selain itu disarankan agar masyarakat memanfaatkan lahanlahan kosong untuk ditanami tumbuan obat sehingga menjadi lahan yang bermanfaat.

Kegiatan penyuluhan Penanggulangan Masalah Kesehatan dalam Kondisi Pasca Bencana berjalan dengan baik walaupun jumlah peserta yang datang tidak memenuhi target. Target peserta yang diharapkan pada sosialisasi ini sebanyak 80 orang akan tetapi yang hadir hanya 43 orang. Hal ini disebabkan oleh waktu pelaksanaan sosialisasi bertepatan dengan musim bercocok tanam.

Penyuluhan dilakukan beberapa kali untuk menyesuaikan waktu dengan penduduk setempat. Selain itu penyuluhan juga dilakukan langsung di rumah warga yang tidak sempat datang ke tempat kegiatan. Pada proses penyuluhan di masing-masing rumah, warga juga menanyakan hal yang sama, yaitu mengenai manfaat obat tradisional yang mereka konsumsi, misalnya bawang putih (Allium sativum), masyarakat biasa mengkonsumsinya sebagai obat antidiabetes khususnya diabetes tipe 2 .

Lisiswanti dan Haryanto (2017) menjelaskan dalam penelitiannya bahwa obat-obatan tradisional saat ini banyak dikembangkan sebagai antidiabetik, diantaranya bulbus bawang putih (Allium sativum Linn.). Unsur kimia utama dalam bawang putih adalah alliin yang merupakan cysteine sulfoxide dan peptida $\gamma$ glutamilcysteine. Bawang putih dalam bentuk serbuk berisi $1 \%$ alliin (S-allyl cysteine sulfoxide). Salah satu bentuk zat aktif bawang putih lainnya adalah allicin (diallyl tiosulfonate atau diallyl disulfide). Pada saat bawang putih dipotong, enzim alinase akan diaktivasi dan alliin berubah menjadi allicin, selanjutnya allicin dimetabolisme menjadi vinyl-ditiines.

Namun yang menjadi permasalahan adalah pada saat yang bersamaan warga tersebut juga mengkonsumsi obat antidiabetes (OAD) yang diberikan oleh rumah sakit ataupun puskesmas. Masyarakat beranggapan bahwa konsumsi bawang putih dan OAD akan mempercepat penurunan gula darah, namun yang terjadi adalah kondisi hipoglikemik parah dikarenakan pemakaian bersamaan dua obat yang menurunkan gula darah. Penurunan gula darah yang terjadi secara drastis dan cepat dapat membahayakan pasien. Maka dari itu dilakukan edukasi kepada masyarakat tentang cara mengkonsumsi obat tradisional tersebut bila dikombinasi dengan OAD oral yang lain. Tentunya dengan menggunakan bahasa yang sederhana agar masyarakat mudah memahaminya.

Sosialisasi berikutnya yang dilakukan adalah pemanfaatan tumbuhan yang ada di sekitar lingkungan sebagai obat tradisional. Lokasi Dusun Ujung Indah berada di pinggir pantai, maka tidak sulit untuk mendapatkan tumbuhan beruwas laut (Scaevola taccada (Gaertn.) Roxb)) yang memiliki efek analgetik/penghilang rasa nyeri yang efektif (Nur, 2018b). Selain menggunakan beruwas laut, masyarakat juga dapat memanfaatkan buah belimbing wuluh (Averrhoa bilimbi L) dan ekstrak daun pepaya (Carica papaya L.) sebagai obat penghilang rasa sakit (analgetik) (Nur, 2018a).

Hasil dari sosialisasi Penanggulangan Masalah Kesehatan dalam Kondisi Pasca Bencana diasumsikan telah sesuai target yaitu pemahaman masyarakat tentang mitigasi dan penanganan darurat masalah kesehatan bila terjadi bencana di wilayah tersebut. Peningkatan pemahaman masyarakat dapat dilihat dengan antusiasme masyarakat dalam memperhatikan setiap materi yang disampikan serta banyaknya pertanyaan yang diajukan masyarakat baik mengenai mitigasi kebencanaan dan pemanfaatan tumbuhan sebagai pengobatan darurat bila terjadi bencana yang tidak diinginkan. Pada sosialisasi tersebut tidak dilakukan pre test dan post test disebabkan keterbatasan waktu yang dimiliki dan juga mempertimbangkan kesibukan warga. Tetapi pada saat akhir sosialisasi, pemateri mengajukan pertanyaan-pertanyaan kepada masyarakat secara lisan mengenai materi yang telah diberikan, dan mayoritas masyarakat dapat menjawab pertanyaan tersebut. Hal itu menjadi indikator keberhasian dari sosialisasi ini.

Kedepannya, diharapkan kepada seluruh warga yang telah hadir dapat menyampaikan pesan penyuluhan kepada masyarakat yang tidak hadir ataupun masyarakat dari desa lainnya. Hal ini karenakan keterbatasan waktu serta jarak antar rumah warga di desa tersebut agak berjauhan.

\section{Simpulan}

Dari hasil pengabdian berupa sosialisasi Penanggulangan Kesehatan dalam Kondisi Pasca Bencana Dusun Ujung Indah, Desa Cilellang, Kecamatan Mallusettasi, Kabupaten Barru, masyarakat telah diberikan pemahaman mengenai hal yang dilakukan pertama kali bila terjadi bencana alam serta masyarakat telah memahami pengobatan darurat yang diberikan bila terjadi keadaan kegawatdaruratan pada pasien yang terluka.

Pada kegiatan sosialisasi selanjutnya diharapkan dapat melakukan simulasi. Maksud dilakukannya simulasi bencana alam agar masyarakat lebih paham lagi apa yang harus dilakukan jika bencana alam yang sebenarnya terjadi di desa tersebut.

\section{Ucapan Terima Kasih}

Terima kasih kepada pimpinan daerah terkait, dalam proses sosialisasi ini: Kepala Desa Cilellang, 
Camat Mallusettasi, Babinsa, Dosen STIKES Pelamonia Makassar, serta mahasiswa yang membantu suksesnya acara, serta terkhusus untuk Warga Dusun Ujung Indah yang menerima tim sosialisasi dengan sangat baik

\section{Daftar Pustaka}

BAPPENAS. (2006). Rencana Aksi Nasional Pengurangan Risiko Bencana 2006-2009. (BAKORNAS PB \& UNDP, Eds.). Jakarta: Perum Percetakan Negara RI.

Faradilla, M. (2018). Peran Tenaga Kefarmasian dalam Penanggulangan Bencana (Role of Pharmacist in Disaster Management). Pharmaceutical Sciences and Research, 5(1), 14-18.

Indonesia. Undang-Undang No 24 Tahun 2007 tentang Penanggulangan Bencana (2007). Jakarta, Indonesia.

Lestari, P., Kusumayudha, S. B., Paripurno, E. T., \& Ramadhaniyanto, B. (2016). Komunikasi Lingkungan untuk Mitigasi Bencana Erupsi Gunung Sinabung. Jurnal ASPIKOM, 3(1), 56. https://doi.org/10.24329/aspikom.v3i1.98

Lisiswanti, R., \& Haryanto, F. P. (2017). Allicin Pada Bawang Putih (Allium sativum) Sebagai Terapi Alternatif Diabetes Melitus Tipe 2. Jurnal Majority, 6(2), 33-38.

Ningrum, M. S. Z. (2015). Peran Perempuan Terhadap Daya Pulih Masyarakat Pasca Bencana Banjir di Dusun Pelangwot, Desa Pelangwot, Kecamatan Laren, Kabupaten Lamongan. Swara Bhumi, 2(2), 15-24.

Nur, A. (2018a). Efek Analgetik Kombinasi Ekstrak Buah Belimbing Wuluh (Averrhoa bilimbi L) dan Ekstrak Daun Pepaya (Carica papaya L.) pada Mencit (Mus musculus). As-Syifaa, 10(02), 213-220.

Nur, A. (2018b). Uji Efek Analgetik dan Antiinflamasi Ekstrak Etanol 70\% Daun Beruwas Laut (Scaevola taccada (Gaertn.) Roxb.) pada Tikus Putih (Rattus norvegicus). Media Farmasi, 14, 6-11.

Nur, A., Fajar, D. R., \& Musdalifah. (2018). Efektivitas Pemberian Rebusan Daun Pandan Wangi (Pandanus amaryllifolius Roxb.) Terhadap Penurunan Kadar Glukosa Darah Mencit (Mus musculus). Media Farmasi, 14(2), 9-14.

Putra, R. I. A. E., \& Faisal, V. (2018). Tantangan Sistem Surveilans Pencegahan Kejadian Luar Biasa Pasca
Bencana di Puskesmas Batusuya Kecamatan Sindue Tombusabora Kabupaten Donggala Tahun 2018. In The 4th UGM Public Health Symposium. Yogyakarta: Berita Kedokteran Masyarakat.

UNISDR. (2009). 2009 Terminologi Pengurangan Risiko Bencana. (Humanitarian Forum, Ed.), 2009 UNISDR Terminology on Disaster Risk Reduction. Indonesia: Asian Disaster Reduction and Response Network (ADRRN). 